Vol. LXVI 2015

\title{
TENSILE TEST FOR ARBOFORM SAMPLES
}

\author{
PLAVANESCU (MAZURCHEVICI) Simona \\ Faculty of Machine Manufacturing and Industrial Management /Department of Machine Manufacturing \\ Technology, “Gheorghe Asachi” Technical University, Iasi, Romania, simona0nikoleta@yahoo.com \\ QUADRINI Fabrizio \\ Department of Industrial Engineering, “Tor Vergata” University, Rome, Italy fabrizio.quadrini@uniroma2.it \\ NEDELCU Dumitru \\ Faculty of Machine Manufacturing and Industrial Management/Department of Machine Manufacturing \\ Technology, “Gheorghe Asachi” Technical University, Iasi, Romania, nedelcu1967@yahoo.com
}

\begin{abstract}
Petroleum-based plastic materials constitute a major environmental problem due to their low biodegradability and accumulation in various environments. Therefore, searching for novel biodegradable plastics is received particular attention. Our studied material, "Liquid wood” produced from lignin, natural fibres and natural additives, is completely biodegradable in natural environment, in normal conditions. This paper presents the behaviour of Arboform and Arboform reinforced with Aramidic Fibers tensile test analysis. Experimental data show that the tensile strength reached an average value of $15.8 \mathrm{MPa}$, the modulus of elasticity after tests is 3513.3MPA for Arboform and for the reinforcement the tensile strength is 23.625MPa, the modulus of elasticity after tests is 3411.5MPA, the materials present a brittle behaviour. The high mechanical properties of newly developed material, better than of other ordinary plastics, recommend it as a potential environment-friendly substituent for synthetic plastics, which are present in all fields of activity.
\end{abstract}

Key words: Arboform, reinforcement, tensile strength, Young modulus

\section{Introduction}

The continued growth of global population is closely related with the increase of their needs. But, haw the natural resources (fossil resources as petroleum and natural gas) are almost depleted the issue of biomaterials from new sources, landfills has captured the attention of social and environmental organizations, academics, businesses markets and governments, becoming an increasingly urgent priority. In this way, a team of researchers from Fraunhofer Institute for Chemical Technology, Pfinztal, Germany, developed a "green" plastic that was advanced by Tecnaro GmbH, a part of that same institute. This newly developed material is being called "liquid wood" (Arboform, Arboblend and Arbofill), made 100\% from renewable plant biomass sources, such as lignin, natural fibres (from annual plant), natural binders (like waxes, resins) and natural additives that improve the rheological properties of material (processing aids, flame retardants, impact modifier), [1].The idea for this bio-plastic came from utilizing the industrial residues of the pulp and paper making business, without the need of cutting trees.

Arboform can be provided in three different variants, depending on the quantity of the mixed components: LV3 Nature, F45Nature and LV5 Nature. The component elements are mixed and tamped without heating in order to obtain compound granules. In case of processing this composite material, can be used the same methods as well as for ordinary plastic materials, however, the injection into moulds being the most used procedure, [1, 3, 4].

This quality thermoplastic engineering material has been shown so far high potential in almost all industrial application areas. These require suitable mechanical properties which can be compared with the mechanical characteristics of conventional plastics, e.g. PA (Polyamide), PE-HD (High Density Polyethylene), [2]. 


\section{Experimental procedure}

The tensile test samples were obtained by injection moulding of "liquid wood" granules, according to DIN EN ISO 527-1: 1993 standard. The moulding injection was carried out a SZ800H standard injection machine available in the Precision Engineering and Nanotechnology Laboratory, Faculty of Machining and Industrial Management, "Gheorghe Asachi" Technical University of Iasi.

The granular materials used in case of this research were Arboform L, V3 Nature, and Arboform L, V3 Nature reinforced with 30\% Aramid Fibres, TWARON D1088 type, produced by TEIJIN. The reinforcement was done by ICEFS COM Company, Savinesti, Neamt, Romania. The material was created in order to improve the injection moulding technology, increase some mechanical properties and to decrease the product prices.

The experimental study plan is over the Taguchi methodology. Method, which tries to satisfy criteria such as: to minimize the tests number and also the price of the experimentation, and to offer the best possible accuracy.

Easier to be studied is the model proposed by Viger and Sisson; the matrix model of the system contain " $I$ " factors, from $F_{1}, F_{2}$, until $F_{i}$ each factor having $n_{i}$ levels, [5]. Three identical specimens are performed for experiments validation. The model matrix proposed takes into consideration six technological parameters each one with two variation levels (Table 1, 2). It is applied matrix modelling using Taguchi method and is writhen the Viger and Sisson model. The coefficients of a type (1) model were determined in the experimental study:

$$
\begin{aligned}
& Z_{T}=M+T_{\text {top }}+t_{i n j}+t_{r}+S_{s}+P_{i n j}+D_{i n j}+P_{i n j} T_{t o p}+P_{i n j} t_{i n j}+P_{i n j} t_{r}+ \\
& +P_{i n j} S_{s}+P_{i n j} D_{i n j}
\end{aligned}
$$

where: M-general average; $\mathrm{T}_{\text {top }}$-melt temperature, $\left[{ }^{0} \mathrm{C}\right]$; $\mathrm{t}_{\text {inj }}$-injection time, $[\mathrm{s}], \mathrm{t}_{\mathrm{r}}$-cooling time, $[\mathrm{s}], \mathrm{S}_{\mathrm{s}}-$ screw displacement, $[\mathrm{mm}], \mathrm{P}_{\text {inj }}$-injection pressure, $[\mathrm{MPa}], \mathrm{D}_{\text {inj- }}$ injection direction, $\left[{ }^{\circ}\right]$.

The most significant influence of the process is exercised by injection pressure followed by melt temperature and injection direction. These are followed by screw speed, injection time and cooling time, which are though less significant. After the orthogonally and number of degrees of freedom conditions analysed, 16 experimental tests have been made.

Table 1. The level values of input parameters for Arboform L, V3 Nature

\begin{tabular}{|c|c|c|c|c|c|c|}
\hline $\begin{array}{c}\text { Input } \\
\text { parameter } \\
\text { levels }\end{array}$ & $\begin{array}{c}\text { melt } \\
\text { temperature } \\
{\left[{ }^{\circ} \mathbf{C}\right]}\end{array}$ & $\begin{array}{c}\text { injection } \\
\text { time } \\
{[\mathbf{s}]}\end{array}$ & $\begin{array}{c}\text { cooling } \\
\text { time } \\
{[\mathbf{s}]}\end{array}$ & $\begin{array}{c}\text { screw } \\
\text { displacement } \\
{[\mathbf{m m}]}\end{array}$ & $\begin{array}{c}\text { injection } \\
\text { pressure } \\
{[\mathbf{M P a}]}\end{array}$ & $\begin{array}{c}\text { injection } \\
\text { direction } \\
{\left[{ }^{\circ}\right]}\end{array}$ \\
\hline First level & 150 & 9 & 18 & 60 & 80 & 0 \\
\hline Second level & 160 & 11 & 25 & 80 & 100 & 90 \\
\hline
\end{tabular}

Table 2. The level values of input parameters for Arboform L, V3 Nature reinforced with Aramid Fibers

\begin{tabular}{|c|c|c|c|c|c|c|}
\hline $\begin{array}{c}\text { Input } \\
\text { parameter } \\
\text { levels }\end{array}$ & $\begin{array}{c}\text { melt } \\
\text { temperature } \\
{\left[{ }^{\circ} \mathbf{C}\right]}\end{array}$ & $\begin{array}{c}\text { injection } \\
\text { time } \\
{[\mathbf{s}]}\end{array}$ & $\begin{array}{c}\text { cooling } \\
\text { time } \\
{[\mathbf{s}]}\end{array}$ & $\begin{array}{c}\text { screw } \\
\text { displacement } \\
{[\mathbf{m m}]}\end{array}$ & $\begin{array}{c}\text { injection } \\
\text { pressure } \\
{[\mathbf{M P a}]}\end{array}$ & $\begin{array}{c}\text { injection } \\
\text { direction } \\
{\left[{ }^{\circ}\right]}\end{array}$ \\
\hline First level & 165 & 10 & 25 & 70 & 120 & 0 \\
\hline Second level & 175 & 15 & 35 & 90 & 140 & 90 \\
\hline
\end{tabular}

The experiments were performed in the Technology and processing Systems Laboratory, Department of Industrial Engineering, “Tor Vergata” University of Rome, Italy.

The most fundamental type of mechanical test that can be performed on a material is the tensile test. Tensile test is a quite simple test, inexpensive and completely standardized. By pulling on a specimen, until failure, it can be quickly determine the reaction to force that is applied in tension on the material from which the sample is made. Properties that are directly measured are tensile strength and maximum elongation, [6].

The test results are used to select a material for an application, for quality control and to predict how a material will react under types of forces.

For tensile test a sample of a material is placed between two fixtures called "grips" which clamp the material. The specimen has two shoulders and a gauge (section) between. The shoulders are large so they 
can be readily gripped; whereas the gauge section has a smaller cross-section so that the deformation and failure can occur in this area. The sample has known dimensions (established according to a standard), like length and cross-sectional area, and is subjected to equal and opposite forces $\mathrm{F}$ (having the direction of longitudinal axis of specimen) pulling at the ends so the material is under tension. The force is increasing until the material breaks, $[6,8]$. The material is experiencing a stress defined to be the ratio of the force to the cross sectional area of the specimen.

Figure 1, shows the typical yield behavior for brittle materials that are subjected to tensile test. Stress $(\sigma)$ is shown as a function of strain $(\varepsilon)$.

Figure 1: Stress- strain characteristic curve for brittle materials, [6, 8]

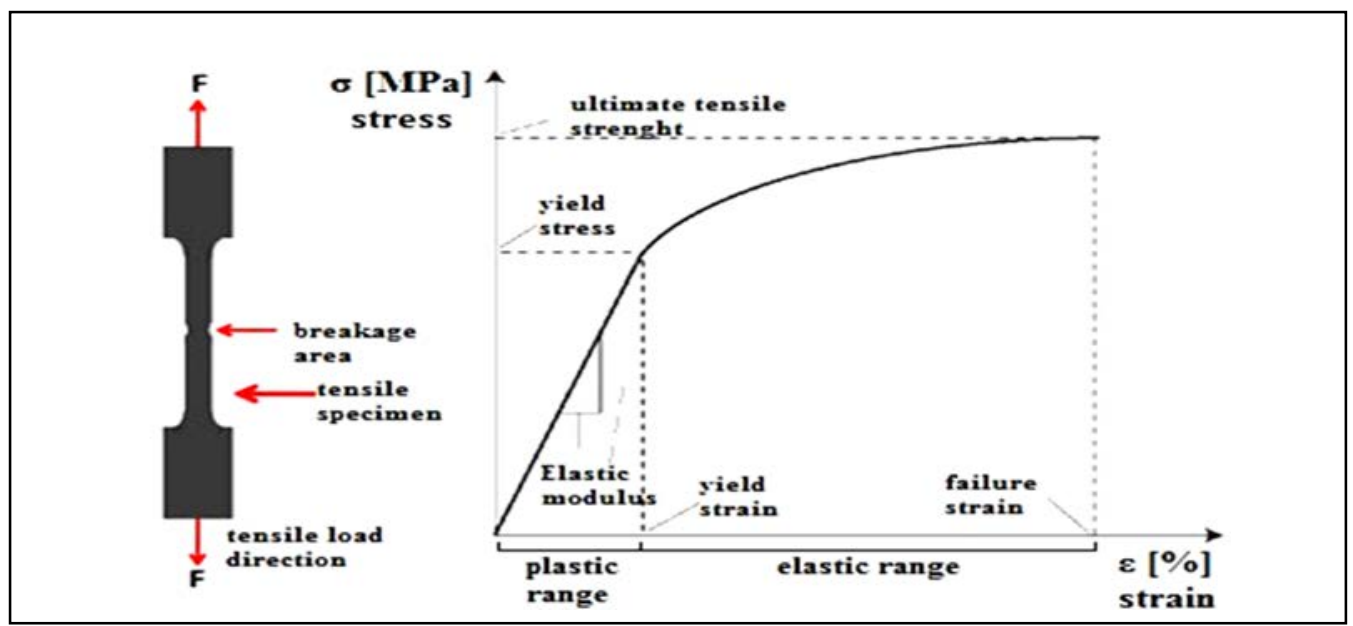

The determination of the mechanical characteristics of Arboform and Arboform reinforced with aramid fibres used in the present research was done according to ISO 527 Standard, [7]. The equation for strength is given by the equation 2, [8]:

$\sigma=\frac{F}{A}$

where: $\sigma$ - strength; F- Force; A- cross-sectional area;

Stress and nominal strain is calculated based on the distance between the grips where the specified specimens is clamped, (equations 3), [6]:

$\varepsilon=\frac{d}{l_{0}} \cdot 100$

where: $l_{0}$ - initial length; $\varepsilon$ - strain; d- crosshead at break; expressed as a percentage.

Modulus of Elasticity or Young's modulus is a measure of material stiffness, which is applied only in the linear region of the curve, and is expressed as, (eq.4).

$E=\frac{F \cdot l_{0}}{A \cdot d}$

where: E- modulus of elasticity/ Young's modulus; F- Force; $l_{0}$ - initial length; A- cross-sectional area; $d$ crosshead at break, [6,8];

Uniaxial tensile tests were carried out on room temperature $\left(23^{\circ} \mathrm{C}\right)$, using a universal testing machine MTS Insight 5, the machine has a Work4-MTS Test Tensile Test Erica 33mm lo software, using a test speed of $0.1 \mathrm{~mm} / \mathrm{min}$ for Arboform and Arboform reinforced with 30\% Aramid Fibres (TWARON D1088 type) the distance between the bins was $108 \mathrm{~mm}$ according to ISO 527-3:2003 standard, [7], width of specimen $10.1 \mathrm{~mm}$, specimen thickness $4 \mathrm{~mm}$, data acquisition rate of $10 \mathrm{~Hz}$.

For each line of the experiment plan, 16 lines, was uniaxial tensile tested a total of three test pieces for calculating the average of the experimental results obtained, the test being carried out until the sample is completely rupture.

\section{Results and discussions}

The average values obtained according to the experimental plan for Arboform and Arboform reinforced with Aramid Fibre samples, during the tensile tests, are presented in Table 3. 
Table 3. Summary of average values and standard deviation of the tensile properties, Arboform vs Arboform reinforced

\begin{tabular}{|c|c|c|c|c|c|c|c|c|}
\hline & \multicolumn{4}{|c}{ Arboform LV3 Nature } & \multicolumn{3}{c|}{ Arboform LV3 Nature reinforced with Aramid } \\
\hline \multirow{2}{*}{$\begin{array}{c}\text { Exp. } \\
\text { no. }\end{array}$} & $\mathbf{\sigma _ { \text { max } }}$ & $\mathbf{E}$ & $\boldsymbol{\varepsilon}$ & $\mathbf{\rho}$ & $\boldsymbol{\sigma}_{\max }$ & $\mathbf{E}$ & $\boldsymbol{\varepsilon}$ & $\boldsymbol{\rho}$ \\
\hline $\mathbf{1}$ & $12.457 \pm 11.2$ & 2222.5 & $0.73 \pm 0.02$ & 1.3617 & $23.61 \pm 0.0002$ & 4011.58 & $0.73 \pm 0.01$ & 1.25 \\
\hline $\mathbf{2}$ & $13.68 \pm 4.5$ & 7881.6 & $0.27 \pm 0.1$ & 1.2465 & $15.84 \pm 60.6$ & 4471.22 & $0.52 \pm 0.1$ & 1.28 \\
\hline $\mathbf{3}$ & $15.72 \pm 0.007$ & 3126.8 & $0.52 \pm 0.004$ & 1.2276 & $27.72 \pm 16.7$ & 3172.72 & $0.93 \pm 0.005$ & 1.26 \\
\hline $\mathbf{4}$ & $13.43 \pm 5.6$ & 5297.7 & $0.33 \pm 0.06$ & 1.2658 & $19.85 \pm 14.2$ & 3487.78 & $0.72 \pm 0.01$ & 1.28 \\
\hline $\mathbf{5}$ & $12.96 \pm 8.08$ & 3778.5 & $0.35 \pm 0.05$ & 1.2028 & $25.8 \pm 4.7$ & 2944.53 & $0.92 \pm 0.004$ & 1.26 \\
\hline $\mathbf{6}$ & $15.2 \pm 0.36$ & 2869.4 & $0.49 \pm 0.009$ & 1.2833 & $16.34 \pm 53.07$ & 4645.73 & $0.55 \pm 0.09$ & 1.29 \\
\hline $\mathbf{7}$ & $19.46 \pm 13.3$ & 2112.1 & $0.94 \pm 0.1$ & 1.2664 & $27.79 \pm 17.34$ & 3267.69 & $0.98 \pm 0.01$ & 1.28 \\
\hline $\mathbf{8}$ & $14.17 \pm 2.6$ & 3267.0 & $0.49 \pm 0.009$ & 1.1815 & $27.5 \pm 15.01$ & 3248.78 & $0.95 \pm 0.008$ & 1.27 \\
\hline $\mathbf{9}$ & $19.86 \pm 16.4$ & 2176.2 & $0.89 \pm 0.09$ & 1.1325 & $23.38 \pm 0.06$ & 3484.09 & $0.77 \pm 0.007$ & 1.29 \\
\hline $\mathbf{1 0}$ & $14.88 \pm 0.8$ & 4229.8 & $0.42 \pm 0.02$ & 1.1140 & $24.33 \pm 0.49$ & 2914.59 & $0.87 \pm 0.0001$ & 1.28 \\
\hline $\mathbf{1 1}$ & $14.39 \pm 1.9$ & 2833.6 & $0.53 \pm 0.003$ & 1.2587 & $25.55 \pm 3.7$ & 2945.8 & $0.97 \pm 0.01$ & 1.26 \\
\hline $\mathbf{1 2}$ & $14.93 \pm 0.7$ & 4101.3 & $0.38 \pm 0.04$ & 1.1864 & $19.21 \pm 19.4$ & 5221.96 & $0.51 \pm 0.1$ & 1.28 \\
\hline $\mathbf{1 3}$ & $16.5 \pm 0.4$ & 3120.3 & $0.71 \pm 0.01$ & 1.2783 & $25.92 \pm 5.2$ & 2624.79 & $1.05 \pm 0.03$ & 1.27 \\
\hline $\mathbf{1 4}$ & $20.15 \pm 18.8$ & 2831.9 & $0.86 \pm 0.07$ & 1.2523 & $26.34 \pm 7.3$ & 2017.25 & $1.49 \pm 0.4$ & 1.27 \\
\hline $\mathbf{1 5}$ & $20.93 \pm 26.2$ & 4893.2 & $1.17 \pm 0.3$ & 1.2676 & $24.39 \pm 0.5$ & 3370.98 & $0.8 \pm 0.003$ & 1.26 \\
\hline $\mathbf{1 6}$ & $14.15 \pm 2.7$ & 4470.9 & $0.34 \pm 0.06$ & 1.2691 & $24.43 \pm 0.6$ & 2754.88 & $0.94 \pm 0.007$ & 1.27 \\
\hline
\end{tabular}

The obtained tensile strength varied for different injection parameters values from 12.457 to $20.93 \mathrm{MPa}$ with standard deviation ranging from 0.007 to 26.2MPa for Arboform LV3 Nature. In case of Arboform reinforced with Aramid Fibres the tensile strength varied for 15.84 to $27.79 \mathrm{MPa}$ with standard deviation ranging from 0.0002 to $60.6 \mathrm{MPa}$. Strain-to-failure results are higher for Arboform reinforced, the average value being $0.85 \%$ and for Arboform $0.58 \%$. The Young's modulus values are not to different, 3513.3MPa for Arboform and 3411.523MPa in case of Arboform reinforced with Aramid Fiber; the material having a brittle behaviour, which is characterized by the fact that the break occurs without any noticeable prior change in the rate of elongation.

By comparing the tensile strength of Arboform and Arboform reinforced, it can be seen in Figure 2, according to the data obtained that the reinforcement, $30 \%$ aramid fibres, leads to a considerable increase of tensile strength, about 8MPa.

Fig.2 Arboform vs. Arboform reinforced, tensile strength values

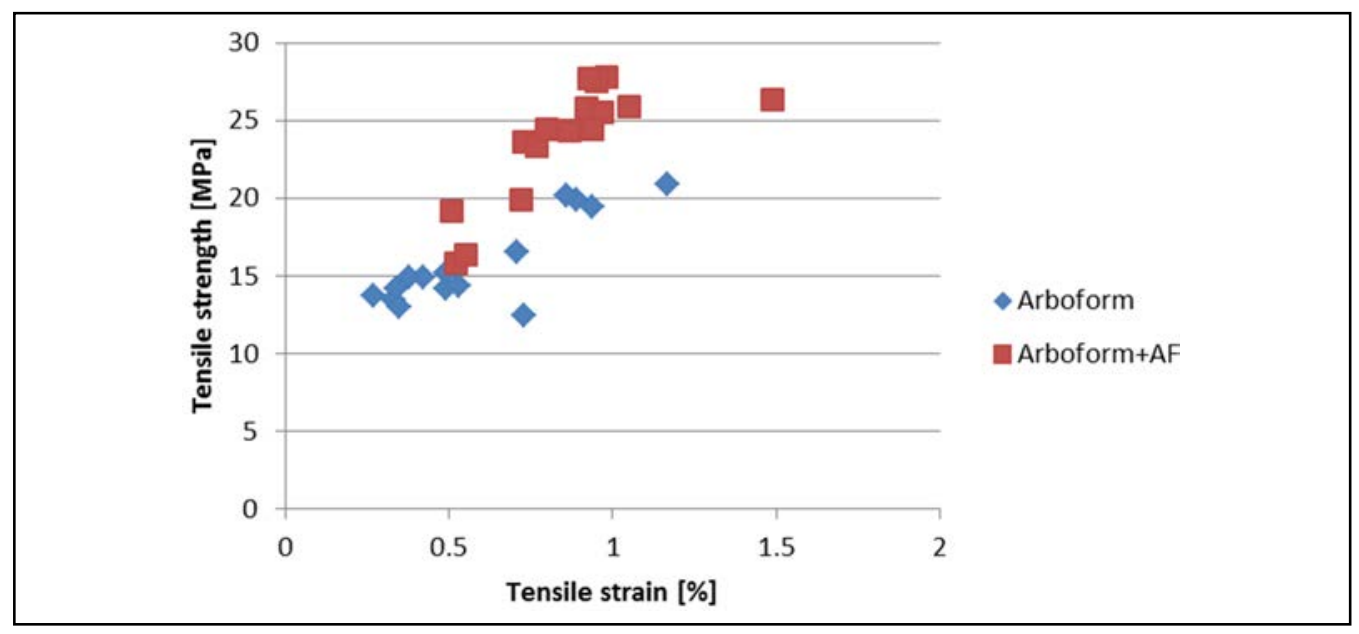


Figure 3 and Figure 4 shows the tensile testing rules. Tensile strength versus tensile strain are plotted to reveal the homogeneity (uniformity) of mechanical properties.

Figure 3: Arboform L, V3 Nature stress-strain curve, 13experiment number

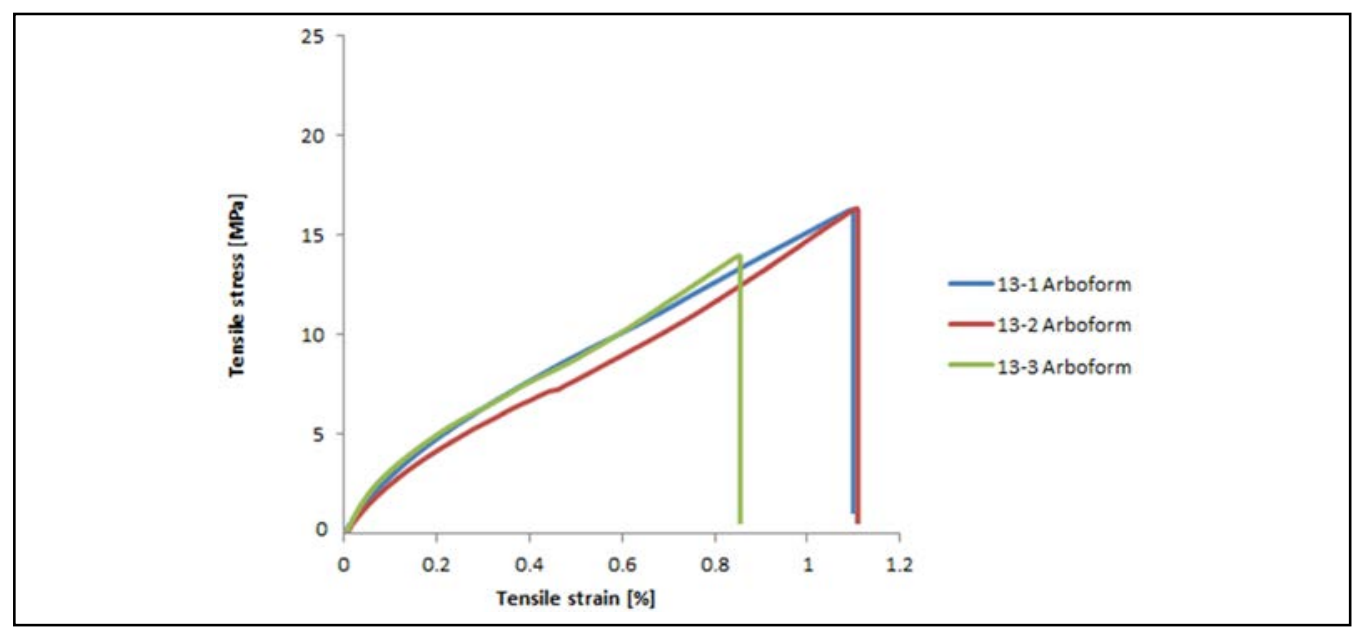

Figure 4: Arboform L, V3 Nature reinforced, tensile stress vs. tensile strain

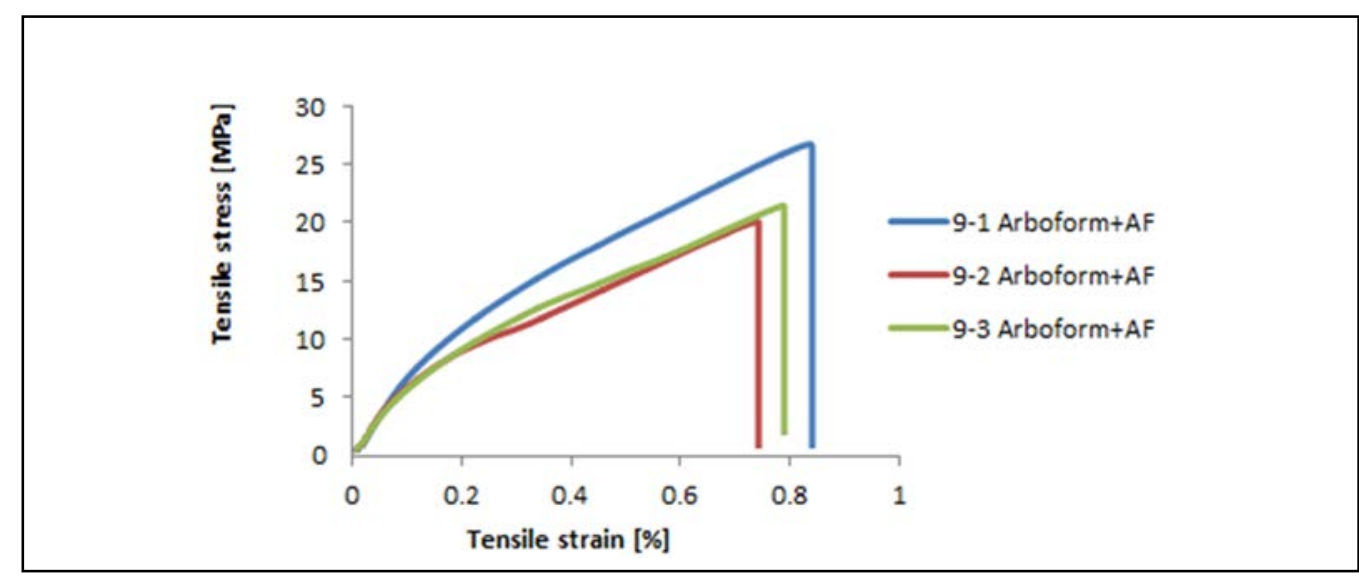

In the below figure, it can be seen that the density of the materials do not suffer major variations after successive changes of input parameters, not influence the material resistance.

Figure 5: Density of tested materials

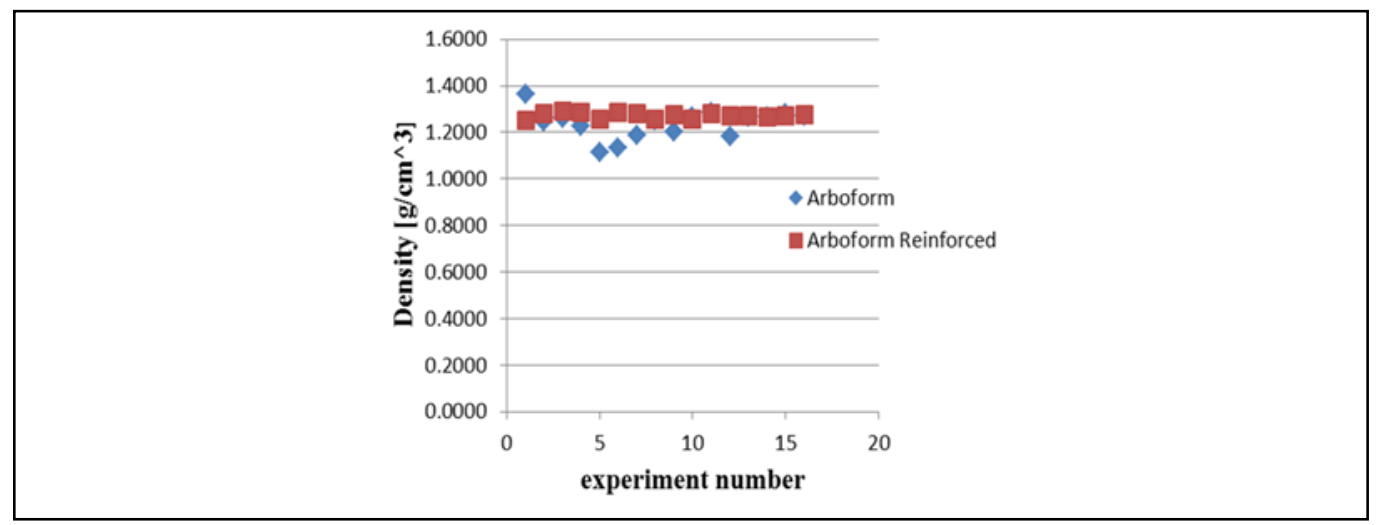

In terms of modulus of elasticity (Young's modulus) after tensile test, the values of these modulus in case of the materials studied are better (2000-6000)MPa than for others plastics such as PA 66 (Polyamide 66) unreinforced: 2000MPa; PP (Polypropylene) unreinforced: 600-1700MPa; PE-HD (High Density Polyethylene), PE-LD (Low Density Polyethylene) and PE-LLD (Linear Low Density Polyethylene): (50 - 500)MPa; PS (Polystyrene): (1200 - 3300)MPa; Wood (beech, across):1500MPa etc. 


\section{Conclusions}

Plastics materials have an important part in our life and can be used in many industrial fields. Due to the extensive versatility, low cost and manufacturing process of plastic allows it to be used in many industrial applications. But, in case of plastics which are obtained from fossil fuels (finite quantities resources) appears the big disadvantage of non-biodegradability and also of waste disposal. So, the use of "liquid wood", $100 \%$ biodegradable material from natural resources which are in unlimited quantities in nature (e.g. lignin, cellulose, natural fibres...) and not effectively used, has received particular attention, [3,4].

Arboform and Arboform reinforced with aramid fibres do to their mechanical properties, which are better than others ordinary plastics, can be used for varying applications with high technical standards request, and also will replace gradually the plastic materials from the market.

The modulus of elasticity in case of the Arboform and Arboform reinforced has better value than for others plastics such as PA 66 unreinforced; PP unreinforced; PE-HD, PE-LD; PE-LLD;PS; Wood (beech, across) etc., [2].

According to research conducted and the results obtained in terms of tensile strength, the "liquid wood" and reinforced version of it can replace the plastic materials that have seized in all activities areas, [1, 3, 4]. The Liquid Wood could find use in applications, such as: jewelries, ornaments, toys, car interiors, electrical industry, furniture industry, mobile phone housings etc.

\section{Acknowledgment:}

This work was supported by the strategic grant POSDRU/159/1.5/S/133652, co-financed by the European Social Fund within the Sectorial Operational Program Human Resources Development 2007 - 2013.

\section{References}

- [1] http://www.tecnaro.de/english/willkommen.htm?section=we, Accessed: 10.03.2015

- [2] http://www.eplas.com.au/assets/125/files/msvc.pdf, Accessed: 10.03.2015

- [3] Srikanth, P., Engineering Applications of Bioplastics and Biocomposites- An overview, Handbook of Bioplastics and Biocomposites Engineering Applications, Published John Wiley \& Sons, New Jersey, pp. 1-14, (2011).

- [4] Nagele, H., Pfitzer, J., Ziegler, L., Inone-Kauffmann, E. R., Eckl, W. and Eisenreich, N.; Lignin Matrix Composites from Natural Resources - ARBOFORM®, Bio-Based Plastics: Materials and Applications, First Edition, Edited by Stephan Kabasci, John Wiley \& Sons. Ltd. Published 2014 by John Wiley \& Sons, Ltd., pp. 89-115, (2014).

- [5] Nedelcu, D., Pruteanu, O.V., Aspecte ale formării canelurilor exterioare prin deformare plastică la rece utilizând metoda Taguchi (Some Aspects of Forming Exterior Grooves by Cold Plastic Deformation using Taguchi Method), Tehnica-Info Publishing House, Chişinău, ISBN 9975-910-96-3, pp. 243-261 (2000).

- [6] http://www.mec.tuiasi.ro/rm/, Accessed: 10.03 .2015

- [7] Tensile Strength, Ultimate, ASTM D638, ISO 527

- [8] Marghitu, D. B., Diaconescu, C. I., Ciocirlan B. O., Mechanics of Materials, Mechanical Engineer's Handbook, Edited by Dan B. Marghitu, ACADEMIC PRESS Publisher, pp. 120-147, (2001). 